\title{
Health risk assessment on human exposed to environmental polycyclic aromatic hydrocarbons pollution sources
}

\author{
Szu-Chich Chen, Chung-Min Liao* \\ Ecotoxicological Modeling Center, Department of Bioenvironmental Systems Engineering, National Taiwan University, Taipei, Taiwan 10617 ROC
}

Received 16 April 2005; received in revised form 15 August 2005; accepted 29 August 2005

Available online 22 November 2005

\begin{abstract}
To assess how the human exposure to environmental carcinogenic polycyclic aromatic hydrocarbons (PAHs) pollution sources generated from industrial, traffic and rural settings, we present a probabilistic risk model, appraised with reported empirical data. A probabilistic risk assessment framework is integrated with the potency equivalence factors (PEFs), age group-specific occupancy probability and the incremental lifetime cancer risk (ILCR) approaches to quantitatively estimate the exposure risk for three age groups of adults, children, and infants. The benzo $[a]$ pyrene equivalents based PAH concentrations in rural, traffic, and industrial areas associated with age group-specific occupancy probability at different environmental settings are used to calculate daily exposure level through inhalation and dermal contact pathways. Risk analysis indicates that the inhalation-ILCR and dermal contact-ILCR values for adults follow a lognormal distribution with geometric mean $1.04 \times 10^{-4}$ and $3.85 \times 10^{-5}$ and geometric standard deviation 2.10 and 2.75, respectively, indicating high potential cancer risk; whereas for the infants the risk values are less than $10^{-6}$, indicating no significant cancer risk. Sensitivity analysis indicates that the input variables of cancer slope factor and daily inhalation exposure level have the greater impact than that of body weight on the inhalation-ILCR; whereas for the dermalILCR, particle-bound PAH-to-skin adherence factor and daily dermal exposure level have the significant influence than that of body weight.
\end{abstract}

(c) 2005 Elsevier B.V. All rights reserved.

Keywords: Polycyclic aromatic hydrocarbons; Benzo[a]pyrene; Potency equivalency factor; Health risk assessment; Environmental pollution

\section{Introduction}

Human cancer causes of skin, lungs, and bladder have always been associated with polycyclic aromatic hydrocarbons (PAHs) (Boffetta et al., 1997). The relationship between cancer and the environment is largely conditioned by investigations involving PAH exposures (Armstrong et al., 2004). Several individual PAHs such as benzo $[a]$ pyrene $(\mathrm{B}[a] \mathrm{P})$, chrysene, indeno $[1,2,3$ $c, d]$ pyrene, and benzo[b]fluoranthene have produced

\footnotetext{
* Corresponding author. Tel.: +88622363 4512; fax: +88622362 6433.

E-mail address: cmliao@ntu.edu.tw (C.-M. Liao).
}

carcinogenic, mutagenic, and genotoxic effects in animal experiments (Thyssen et al., 1981; Deutsch-Wenzel et al., 1983). Somers et al. $(2002,2004)$ have also found out that air pollution enriched with PAHs has been shown to include heritable (paternal germ-line) mutations in mice.

More recently, PAHs have been associated with elevated levels of DNA adducts (PAH-DNA adducts) and P53 mutations in persons who smoke or are exposed to PAH in the workplace and ambient air (Alexandrov et al., 2002; Gaspari et al., 2003). Perera et al. (2002) has also indicated that airborne PAHs have been implicated in human reproductive effects, PAH-DNA adducts in newborns as well as preterm birth and 
intrauterine growth restriction. Although exposure to environmental PAHs has been based on the assumption that inhalation was the primary route (Venkataraman and Raymond, 1998), dermal contact is increasingly taken into account (ATSDR, 1990; Tsai et al., 2001).

The risk associated with human exposure to atmospheric PAHs is highest in cities, considering the density of population, increasing vehicular traffic, and scarce dispersion of the atmospheric pollutants. In Taiwan region, several significant contributor to PAHs sources had been sampled such as stationary industrial combustion: steel and iron industries (Yang et al., 2002) with a mean total-PAHs concentrations measured to be $1020 \mu \mathrm{g} \mathrm{m} \mathrm{m}^{-3}$, traffic vehicles exhaust: motorcycle (Yang et al., 2005) and highway toll station (Tsai et al., 2004) with a mean total-PAHs concentrations ranged from $8280-12300 \mathrm{ng} \mathrm{m}^{-3}$. Fang et al. $(2004 a, b, c)$ indicated that mean total PAHs levels at industrial, urban, and rural areas in central Taiwan region ranged from 1232-1650, 700-1740, and 610$831 \mathrm{ng} \mathrm{m}^{-3}$, respectively.

However, occurrence of PAHs in ambient air causes particular concern due to the continuous nature of exposures and the size of populations at risk, especially in urban, suburban and industrial areas. Therefore, in light of the mutagenicity, carcinogenicity and ubiquity of some PAHs in the atmosphere, the setting of air quality standards and guidelines to limit human exposure should be of primary concern for public health policy. However, it is complicated to derive scientifically the standards or guidelines based on relatively limited empirical data, owing to the difficulties in interpreting heterogeneous experimental and epidemiological findings (Tsai et al., 2001).

Currently, no information on the human cancer risk assessment for specific-age groups related to environmental PAHs pollution sources is available in Taiwan region. Furthermore, identification of the most dangerous environmental PAHs and their mode of action in producing specific health effects remain uncertain and difficult to quantify the exposure risk precisely. To reduce the potential risk of harmful negative health consequences and problems, we suggest that risk analyses be taken seriously to characterize the impact of PAHs in the human environment. Fang et al. $(2004 a, b, c)$ have been reported the relevant measurements of PAHs in industrial, urban, and rural areas and these measurements were sufficiently to motivate the most serious kind of concern for personal exposure to environmental carcinogenic PAHs. We were stimulated to develop a probabilistic risk assessment framework to evaluate the carcinogenic risk from personal exposure to environmental PAHs in industrial, urban, and rural areas.

The objective of this study is to develop an integrated environmental exposure risk model that incorporates inhalation and dermal contact from atmospheric PAHs existing in industrial, urban, and rural areas in Taiwan region. The risk model is intended to apply to general Taiwanese population. A detailed sensitivity and uncertainty analyses are conducted, and the results are used to identify critical input variables requiring further study. We employed a quantitative risk assessment method used for PAHs based on $\mathrm{B}[a] \mathrm{P}$ equivalent concentration from animal studies. Several studies have also documented the impact that the outdoor air (Ando et al., 1996; Li and Ro, 2000; Naumova et al., 2002), and more specifically traffic (Kingham et al., 2000; Fisher et al., 2000), has on the quality of indoor air. We were extended our risk analysis to include PAH levels in indoor air in light of these findings.

\section{Materials and methods}

\subsection{Data reanalysis}

There is relatively little empirical data in environmental PAHs sources because the experiments are complicated. Accordingly, we must rely on data reanalysis technique together with whatever empirical data is available. Here, we adopted three published empirical data in total PAHs concentrations and particle-bound PAHs concentrations sampled from industrial, traffic, and rural areas in Taiwan region.

Fang et al. (2004a) selected two sampling sites situated at Taichung Industry Park and suburban area (Tunghai University) in central Taiwan to measure 21 individual PAH concentrations with $48 \mathrm{~h}$ consecutive sampling $(n=23)$ from August 2002 to July 2003 in that the meteorological conditions such as temperature, relative humidity, wind speed, and atmospheric pressure were also monitored. Taichung Industry Park represents the typical large-scale multiple industry with more than 800 factories. The sampling site is located on the roof of a pharmaceutical factory $(18 \mathrm{~m}$ in height), situated at the center of Taichung Industry Park. Suburban area (Tunghai University) is a background site to compare with the neighbor Industrial Park. The sampling heights were set in the range of $1-1.5 \mathrm{~m}$ above ground level to simulate the breathing zone. The instruments were calibrated using at least five standard concentrations covering the concentration of interest for ambient air work. The calibration curve had significant correlated with the linear regression profile 
$\left(r^{2}=0.998\right)$. The average recovery efficiency of PAH was $86 \%$. The total 21 PAHs concentration at Taichung Industrial Park and Tunghai university were measured to be $1560.1 \pm 1429.4($ mean $\pm \mathrm{sd})$ and $734.1 \pm 541.0$ $\mathrm{ng} \mathrm{m}^{-3}$, respectively. Fang et al. (2004b) measured the PAHs concentration at three sampling sites $(n=12)$ situated at Taichung Industry Park, rural area (Tunghai University), and urban site from August 2002 to December 2002 in that PAH concentration, size distribution, and estimated PAHs dry deposition fluxes and health risk were also determined. The mean concentrations of total PAHs in ambient air at industrial, urban, and rural in central Taiwan, Taichung were measured to be 1652,1185 , and $834.1 \mathrm{ng} \mathrm{m}^{-3}$, respectively.

We have also adopted the data from Tsai et al. (2004) for PAHs concentrations measured at highway toll station to account for the traffic pollution sources in that they collected 48,35 , and 33 personal PAH samples from booth attendants of the dayshift (08:00 AM16:00 PM), nightshift (16:00 PM-00:00 AM), and latenight (00:00 AM-08:00 AM), respectively. Their study showed the average recovery efficiency of PAHs was $85 \%$. The limit of detections of the $21 \mathrm{PAH}$ compounds were determined based on the analysis of serial dilutions of PAH standards.

A useful for estimation of the health risk posed by multi-component PAH exposure is based on the use of the individual compound's potency equivalency factor (PEF) relative to $\mathrm{B}[a] \mathrm{P}$ based on a PEF scheme developed by Collins et al. (1998). In a first step, a $\mathrm{B}[a] \mathrm{P}$ equivalent concentration $\left(\mathrm{B}[a] \mathrm{P}_{\mathrm{eq}}\right)$ is calculated by the multiplication of the individual PAH concentration by its PEF. The carcinogenic potency of all considered PAHs can then be estimated as the sum of each individual $\mathrm{B}[a] \mathrm{P}_{\text {eq. }}$. Table 1 lists the PAHs and the PEFs used in the calculation associated with the cancer evidence of individual PAH compound. Nisbet and LaGoy (1992) and Collins et al. (1998) have summarized the assumptions underlying the use of the PEF approach to the calculation of exposure to PAHs.

\subsection{Occupancy probability and daily exposure level}

Here we define an occupancy probability (OP) to quantify the likelihood of the time a person spends in a specific setting (Fig. 1). The OP is a practical assumption according to daily routine activities or daily working logs for ordinary adults, children, and infants. In the future study, however, the detailed case investigation is essential to provide the reliable data required.

We assumed that a cohort lived at rural and their workplace or children's school nearby an industrial
Table 1

Potency equivalency factors (PEF) and molecular weight for individual PAHs relative to $\mathrm{B}[a] \mathrm{P}$ (Nisbet and LaGoy, 1992) used in this study

\begin{tabular}{|c|c|c|}
\hline Compound & Molecular weight $\left(\mathrm{g} \mathrm{mol}^{-1}\right)$ & PEF \\
\hline Naphthalene (Nap) & 128 & 0.001 \\
\hline Acenaphthylene (AcPy) & 152 & 0.001 \\
\hline Acenaphthene (AcP) & 154 & 0.001 \\
\hline Fluorene (Flu) & 165 & 0.001 \\
\hline Phenanthrene (PA) & 178 & 0.001 \\
\hline Anthracene (Ant) & 178 & 0.01 \\
\hline Fluoranthene (FL) & 202 & 0.001 \\
\hline Pyrene (Pyr) & 202 & 0.001 \\
\hline Cyclopenta $[c, d]$ pyrene (CYC) & 228 & $0.1^{\mathrm{a}}$ \\
\hline Benzo $[a]$ anthracene $(\mathrm{BaA})$ & 228 & 0.1 \\
\hline Chrysene (CHR) & 228 & 0.01 \\
\hline Benzo $[b]$ fluoranthene $(\mathrm{BbF})$ & 252 & 0.1 \\
\hline Benzo $[k]$ fluoranthene $(\mathrm{BkF})$ & 252 & 0.1 \\
\hline Perylene (PER) & 252 & $0.001^{\mathrm{a}}$ \\
\hline Benz $[e]$ pyrene $(\mathrm{BeP})$ & 252 & $0.01^{\mathrm{a}}$ \\
\hline Benzo $[a]$ pyrene $(\mathrm{BaP})$ & 252 & 1 \\
\hline Indeno[1,2,3-c,d]pyrene (IND) & 276 & 0.1 \\
\hline Dibenz $[a, h]$ anthracene (DBA) & 278 & $1^{\mathrm{a}}$ \\
\hline Benzo $[b]$ chrycene $(\mathrm{BbC})$ & 278 & NA \\
\hline Benzo $[g, h, i]$ perylene (BghiP) & 276 & 0.01 \\
\hline Coronene (COR) & 300 & $0.001^{\mathrm{a}}$ \\
\hline
\end{tabular}

${ }^{\text {a }}$ Value adopted from Malcom and Dobson (1994).

park and they were vulnerably exposed to PAHs pollution from traffic when they went to workplace or school. We divided a 24 -h period into five time intervals as $j=1,2,3,4$, and 5 representing the time periods from 00:00-07:00, 07:00-09:00, 09:0017:00, 17:00-19:00, and 19:00-24:00, respectively. We further denote $j=1$ and 5 are the time intervals spent at rural (home), $j=2$ and 4 are the time intervals spent in commuting, and $j=3$ is the time interval and spent in working or at school (Fig. 1). We assumed the OP within each period followed a uniform distribution and the summation of the daily basis OP at 24-h for rural, traffic, and industrial settings was equal to 1 .

The indoor PAHs levels in rural (home) can be estimated by knowing the PAHs concentration in rural associated with the average indoor/outdoor $(I / O)$ ratio. Here we adopted an average PAHs $I / O$ ratio of 1.2 measured by Li and Ro (2000) in the rural areas of the northern Taiwan region. Fig. 1 demonstrates that the infant OP has the highest value at rural setting, whereas children have the higher than those of others at traffic setting. At industry setting, adult has higher OP than those of others.

The $\mathrm{B}[a] \mathrm{P}_{\mathrm{eq}}$-based $\mathrm{PAH}$ concentration in rural, traffic, and industrial areas associated with age groupspecific OP values at different settings are used to calculate daily exposure level through inhalation and 

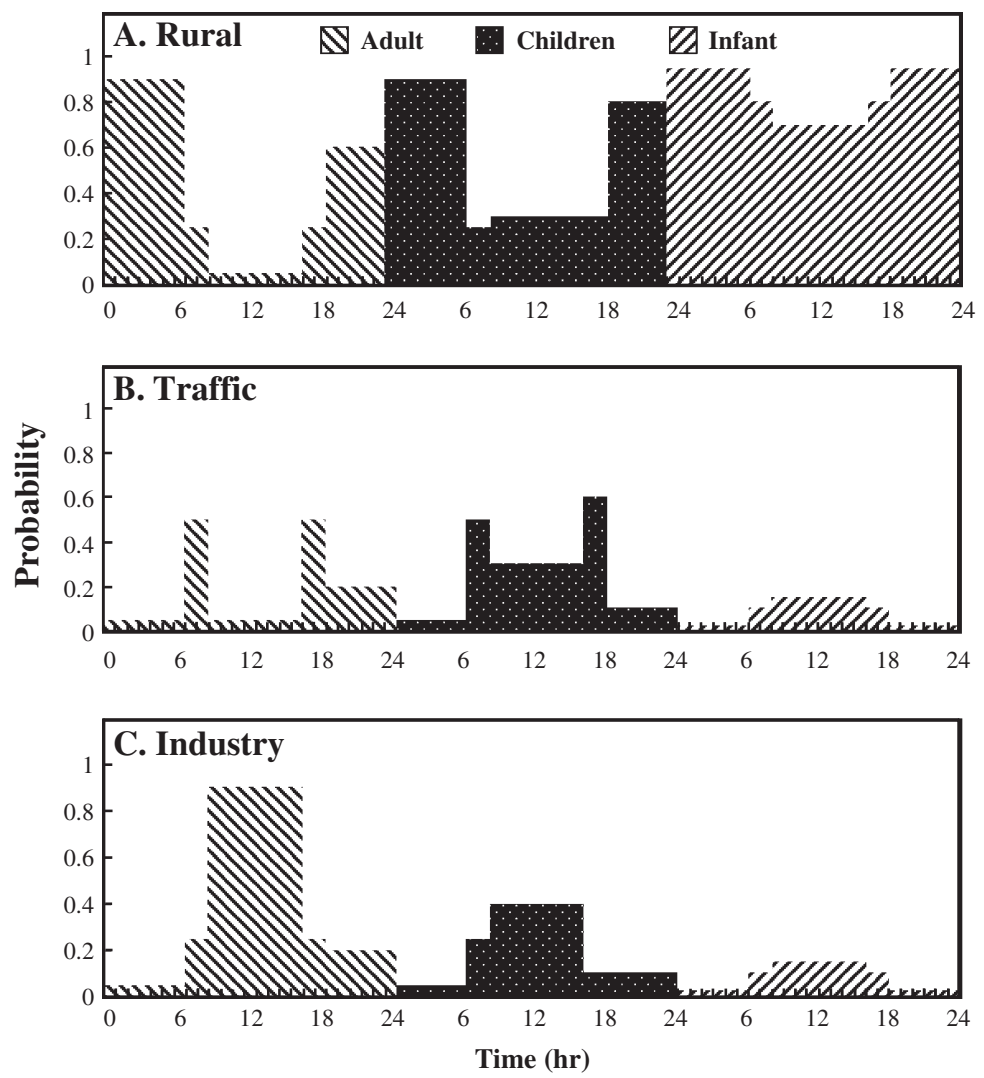

Fig. 1. Human occupancy probability patterns for three age groups of adult, children, and infant at (A) rural, (B) traffic, and (C) industry settings.

dermal contact. Daily exposure level for a specific age group can be calculated as,

$E_{I}=\sum_{i=1}^{3}\left[\sum_{j=1}^{5} \mathrm{OP}_{i j} \cdot\left(a_{i} C_{i}\right) \cdot\left(\frac{1}{24} \mathrm{OT}_{j}\right) \cdot \mathrm{IR}_{j}\right]$,

where $E_{I}$ is the daily exposure level for inhalation for age group in three environmental settings $\left(\mathrm{ng} \mathrm{day}^{-1}\right)$, $a_{i}=1.2$ is the average PAHs $I / O$ ratio for rural setting $(i=1)$ otherwise $a_{i}=1, \mathrm{OP}_{i j}$ is the OP value in the $j^{\text {th }}$ time interval $(j=1,2,3,4$, and 5$)$ in environmental setting $i(i=1,2$, and 3 represent rural, traffic, and industrial setting, respectively), $C_{i}$ is the PAHs concentration in environmental setting $i\left(\mathrm{ng} \mathrm{m}^{-3}\right), \mathrm{OT}_{j}$ is the occupancy time for the $j^{\text {th }}$ time interval (hr), $\mathrm{IR}_{j}$ is the inhalation rate in the $j^{\text {th }}$ time interval $\left(\mathrm{m}^{3}\right.$ day $\left.^{-1}\right)$ when $j=1$ and 5 are the resting activity and $j=2,3$, and 4 are the active activity.

We can also adopt Eq. (1) to calculate the daily exposure level for dermal contact as

$E_{\mathrm{D}}=\sum_{i=1}^{3}\left[\sum_{j=1}^{5} \mathrm{OP}_{i j} \cdot\left(a_{i} C_{\mathrm{d}}\right) \cdot\left(\frac{1}{24} \mathrm{OT}_{j}\right)\right]$, where $E_{\mathrm{D}}$ is the daily exposure for dermal contact ( $\mu \mathrm{g}$ $\mathrm{g}^{-1}$ ) and $C_{\mathrm{d}}$ is the particle-bound PAH concentration $\left(\mu \mathrm{g} \mathrm{g}^{-1}\right)$. Here, adult are defined as individuals from ages 20 to 70 year, children are defined as individuals from ages 5 to 19 year, whereas infant are defined as individuals from ages 0 to 1 year.

\subsection{Incremental lifetime cancer risk (ILCR) model}

A probabilistic risk model integrates the potency equivalence factors (PEFs), human OP and the ILCR approach to quantitatively estimate the exposure risk for three age groups of adult, children, and infant. The ILCR model for human inhalation is defined as,

$R=\frac{E_{I} \cdot\left(\operatorname{CSF}_{i}\left(\frac{\mathrm{BW}}{70}\right)^{1 / 3}\right) \cdot \mathrm{EF} \cdot \mathrm{ED}}{\mathrm{BW} \cdot \mathrm{AT}} \times c f$,

where $R$ is the incremental individual lifetime cancer risk, $E_{I}$ is the daily exposure level for inhalation (ng day $\left.^{-1}\right), \mathrm{CSF}_{\mathrm{i}}$ is the inhalation carcinogenic slope factor $\left(\mathrm{mg} \mathrm{kg}^{-1} \text { day }^{-1}\right)^{-1}$, EF is the exposure frequency (day year $^{-1}$ ), ED is the exposure duration (year), AT is the 
averaging time for carcinogenic (day), BW is the body weight $(\mathrm{kg})$, and $c f$ is the conversion factor $\left(10^{-6}\right)$. We treated $E_{I}, \mathrm{CSF}_{\mathrm{i}}$, EF and BW in Eq. (3) probabilistically.

The ILCR model for dermal contact pathway is defined as,

$$
R=\frac{E_{\mathrm{D}} \cdot\left(\mathrm{CSF}_{\mathrm{d}}\left(\frac{\mathrm{BW}}{70}\right)^{1 / 3}\right) \mathrm{AB} \cdot \mathrm{SA} \cdot \mathrm{EV} \cdot \mathrm{AF}_{\mathrm{d}} \cdot \mathrm{EF} \cdot \mathrm{ED}}{\mathrm{BW} \cdot \mathrm{AT}}
$$

where $E_{\mathrm{D}}$ is the daily exposure level for dermal contact $\left(\mu \mathrm{g} \mathrm{g}^{-1}\right)$ (particle-bound PAHs concentration), $\mathrm{CSF}_{\mathrm{d}}$ is the cancer slope factor for dermal contact $\left(\mathrm{mg} \mathrm{kg}^{-1}\right.$ day $\left.^{-1}\right)^{-1}, \mathrm{AB}$ is the dermal adsorption fraction (dimensionless), SA is the dermal surface area exposed $\left(\mathrm{cm}^{2}\right)$, $\mathrm{EV}$ is the event frequency (event day $\left.{ }^{-1}\right), \mathrm{AF}_{\mathrm{d}}$ is the particle-to-skin adherence factor $\left(\mathrm{mg} \mathrm{cm}^{-2}\right.$ event $\left.^{-1}\right)$. We treated $E_{\mathrm{D}}, \mathrm{AB}, \mathrm{SA}, \mathrm{AF}_{\mathrm{d}}$ and $\mathrm{BW}$ in $\mathrm{Eq}$. (4) probabilistically. The total incremental lifetime cancer risk is the sum of risks associated with each exposure route.

The ILCRs for adults, children, and infants could be calculated respectively as follows. For adults: $\mathrm{ILCR}=\sum_{i=20}^{70} R_{i} / 51$, for children: ILCR $=\sum_{i=5}^{19} R_{i} / 15$, and for infants: $I L C R=\sum_{i=0}^{1} R_{i}$.
The potency of $\mathrm{B}[a] \mathrm{P}$ is based on the $95 \%$ upper confidence limit of the linearized multistage model (OEHHA, 1993) applied to the incidence of respiratory tumors after inhalation exposure in hamsters (Thyssen et al., 1981). Collins et al. (1991) have estimated the cancer slope factor for $\mathrm{B}[a] \mathrm{P}$ inhalation exposure based on three different hamster inhalation rates of 0.037 , 0.063 , and $0.158 \mathrm{~m}^{3} \mathrm{day}^{-1}$ and resulted in the CSF values of $6.1,3.8$, and $1.3\left(\mathrm{mg} \mathrm{kg}^{-1} \mathrm{day}^{-1}\right)^{-1}$, respectively. We averaged those three CSF values and logtransformed appropriately to a lognormal distribution with a geometric mean $3.14\left(\mathrm{mg} \mathrm{kg}^{-1} \text { day }^{-1}\right)^{-1}$ and a geometric standard deviation 1.80. For exposure to $\mathrm{B}[a] \mathrm{P}$ through dermal contact pathway, the potency of $37.47\left(\mathrm{mg} \mathrm{kg}^{-1} \mathrm{day}^{-1}\right)^{-1}$ based on incidence of skin tumors in mice (Schmahl et al., 1977) could be used (Hussain et al., 1998). The cancer slope factors are normalized to account for extrapolation to a different body weight from standard of $70 \mathrm{~kg}$.

Table 2 shows the selected types of probability distribution for random variables including the inhalation risk and dermal contact risk parameters. The SA describes the amount of skin exposed to the contaminated media. The amount of skin exposed depends upon the exposure scenarios. The adult in commercial/industrial workplace was assumed to wear a

Table 2

Risk parameters considered as random variables (lognormal distribution with geometric mean and geometric stand deviation: LN (gm, gsd)) for different age groups

\begin{tabular}{|c|c|c|c|c|}
\hline Definition & units & Infant & Children & Adult \\
\hline \multicolumn{5}{|l|}{ Population parameter } \\
\hline Age & year & $0-1$ & $5-19$ & $20-70$ \\
\hline Body weight $(\mathrm{BW})^{\mathrm{a}}$ & $\mathrm{kg}$ & $\mathrm{LN}(6.79,1.27)$ & $\mathrm{LN}(36.24,1.05)$ & $\mathrm{LN}(59.78,1.07)$ \\
\hline
\end{tabular}

Inhalation risk parameter

Daily exposure level $\left(E_{I}\right)$

Inhalation rate $\left(\mathrm{IR}_{\mathrm{air}}\right)^{\mathrm{b}}$

$\begin{array}{llll} & \mathrm{ng} \mathrm{day}^{-1} & \mathrm{LN}(257,1.96) & \mathrm{LN}(1724,1.83) \\ \text { Resting } & \mathrm{m}^{3} \text { day }^{-1} & \mathrm{LN}(2.75,1.38) & \mathrm{LN}(7.71,1.27) \\ \text { Active } & & \mathrm{LN}(5.96,1.49) & \mathrm{LN}(24.87,1.38)\end{array}$

$\mathrm{LN}(1687,1.70)$

$\mathrm{LN}(9.01,1.26)$

$\operatorname{LN}(32.74,1.14)$

Dermal risk parameter

Daily exposure level $\left(E_{\mathrm{D}}\right)$

Dermal adsorption fraction $(\mathrm{AB})^{\mathrm{c}}$

Dermal surface exposure (SA) ${ }^{\mathrm{d}}$

Events frequency $(\mathrm{EV})^{\mathrm{c}}$

Dermal adherence rate $\left(\mathrm{AF}_{\mathrm{d}}\right)^{\mathrm{c}}$

$\begin{array}{ll}\mu \mathrm{g} \mathrm{g}^{-1} & \mathrm{LN}\left(4.8 \times 10^{-4}, 1.91\right) \\ - & \mathrm{LN}(0.13,1.26) \\ \mathrm{cm}^{2} & \mathrm{LN}(719,1.19) \\ \text { event year }^{-1} & 1 \\ \mathrm{mg} \mathrm{cm}^{-2} \text { event }^{-1} & \mathrm{LN}(0.04,3.414)\end{array}$

$\mathrm{LN}\left(8.8 \times 10^{-4}, 1.85\right)$

$\mathrm{LN}(0.13,1.26)$

$\mathrm{LN}(2196,1.08)$

1

$\mathrm{LN}(0.04,3.404)$
$\mathrm{LN}\left(7.1 \times 10^{-4}, 1.77\right)$

$\mathrm{LN}(0.13,1.26)$

$\mathrm{LN}(3067,1.06)$

1

$\mathrm{LN}(0.02,2.668)$

\section{Risk model parameter}

Exposure frequency $(\mathrm{EF})^{\mathrm{e}}$

Averaging time (AT) ${ }^{\mathrm{c}}$

day year ${ }^{-1} \quad \mathrm{LN}(252,1.01)$

day 25550
$\mathrm{LN}(252,1.01)$ 25550
$\mathrm{LN}(252,1.01)$ 25550

\footnotetext{
${ }^{a}$ Adapted from Department of Health, ROC (http://www.doh.gov.tw/cht/index.aspx\#).

b Adapted from ICRP 66 (ICRP, 1994).

c Adapted from USEPA (2001).

d Adapted form USEPA (1992).

e Adapted from Central Personnel Administration, ROC (http://www.cpa.gov.tw/cpa2004/pfattend/download/EXWT93102901.doc).
} 
short-sleeved shirt, long pants, and shoes; therefore, the exposed skin surface is limited to the head, hands, and forearms. We can calculate the age group SA according to the recommended value from USEPA (1992). Recommended dermal absorption fraction from soil for $\mathrm{B}[a] \mathrm{P}$ and other PAHs followed a lognormal distribution with a geometric mean 0.13 and geometric standard deviation 1.26 (USEPA, 2001). An averaging time of 365 day year $^{-1}$ for 70 year (i.e., $\mathrm{AT}=25,550$ day) was used to characterize lifetime exposure for cancer risk calculation.

\subsection{Uncertainty analysis}

Uncertainty arises from estimation of both exposure and effects. Incorporating variability and uncertainty into risk calculation results a more realistic view about the real distribution of risk. In order to quantify this uncertainty and its impact on the estimation of expected risk, a Monte Carlo simulation was implemented. We performed independent runs at 1000, 4000, 5000 , and 10,000 iterations with each parameter sampled independently from the appropriate distribution at the start to test the convergence and the stability of the numerical output. The result shows that 5000 iterations are sufficient to ensure the stability of results. A confidence interval for expected risk was determined on the basis of the 2.5th and 97.5th quartiles of the simulation outcomes.

Sensitivity analysis identified the most significant parameters that were included in the uncertainty and variability analysis. The sensitivity of each variable relative to one another was assessed by calculating rank correlation coefficients between each input and output during simulations and then estimating each input contribution to the output variance by squaring the output variance and normalizing to $100 \%$. The Monte Carlo simulation and sensitivity analysis were implemented using Crystal Ball software (Version 2000.2, Decisioneering, Inc., Denver, CO, USA).

\section{Results}

\subsection{Total PAHs concentration for environmental PAHS pollution sources}

The median total PAHs and the median $\mathrm{B}[a] \mathrm{P}_{\text {eq }}$ concentrations of inhalation exposure at rural, industrial, and traffic settings are estimated to be 645 and 18.7; 1200 and 25.67; and 10611.28 and $158.5 \mathrm{ng}$ $\mathrm{m}^{-3}$, respectively (Fig. 2A, B), whereas median particle-bound PAHs and median $\mathrm{B}[a] \mathrm{P}_{\text {eq }}$ concentrations for dermal contact exposure are estimated to be 68.48 and $6.20 ; 107.8$ and 5.48; and 1103.97 and $127.84 \mathrm{ng} \mathrm{m}^{-3}$, respectively, at rural, industrial and traffic settings (Fig. 2C, D). Data reanalysis also demonstrates that $\mathrm{B}[a] \mathrm{P}_{\text {eq }}$ levels in the traffic setting were much higher than those measured in rural and industrial settings where $\mathrm{B}[a] \mathrm{P}_{\text {eq }}$ levels were slightly closed (Fig. 2B, D).

\subsection{Daily exposure B[a]Peq concentration}

The daily exposure $\mathrm{B}[a] \mathrm{P}_{\mathrm{eq}}$ concentration can be estimated from Eqs. (1) and (2) associated with age group-specific OP values at different environmental settings (Fig. 1) through the potential exposures of the normal daily activities or working logs. The predicted probability density functions of daily exposure $\mathrm{B}[a] \mathrm{P}_{\text {eq }}$ concentration based on the inhalation and dermal contact are shown in Fig. 3A, C in that box and whisker plots are used to represent the uncertainty in that boxes show 25 th and 75 th percentiles and whiskers are 2.5th and 97.5th percentiles (Fig. 3B, D). We practically used the average outdoor particle concentration of $60.29 \mu \mathrm{g} \mathrm{m}^{-3}$ measured from Atmospheric Monitor Station of Taiwan Environmental Potency Agency during 2002 to 2003 to carefully convert the PAHs concentration in unit of $\mathrm{ng} \mathrm{m}^{-3}$ (Fig. 2D) to $\mu \mathrm{g} \mathrm{g}^{-1}$ (Fig. 3C, D).

The median $\mathrm{B}[a] \mathrm{P}_{\mathrm{eq}}$ concentration of inhalation exposure are estimated to be 1628, 1590, and 252 ng day $^{-1}$, respectively, whereas the median $\mathrm{B}[a] \mathrm{P}_{\mathrm{eq}}$ concentration of dermal contact exposure are calculated to be $7.0 \times 10^{-4}, 8.7 \times 10^{-4}$, and $4.8 \times 10^{-4} \mu \mathrm{g}$ $\mathrm{g}^{-1}$, respectively, for adults, children, and infants (Fig. 3B, D). In inhalation exposure, the $\mathrm{B}[a] \mathrm{P}_{\mathrm{eq}}$ levels for adults and children are nearly closed and higher than that of infants, whereas in dermal exposure, the $\mathrm{B}[a] \mathrm{P}_{\text {eq }}$ level of children is slightly higher than that of adults and both are higher than that of infants (Fig. 3B, D).

\subsection{Inhalation, dermal, and total incremental lifetime cancer risk (ILCR)}

According to the daily exposure level of dermal contact and inhalation exposure, we can estimate the inhalation and dermal ILCRs (Fig. 4). Fig. 4A1-A3 indicate that the inhalation ILCRs for adults, children, and infants age group follow lognormal (LN) distributions of $\mathrm{LN}\left(1.04 \times 10^{-4}, 2.10\right), \mathrm{LN}\left(6.47 \times 10^{-6}, 2.21\right)$, and $\mathrm{LN}\left(5.50 \times 10^{-8}, 2.36\right)$, respectively. Fig. 4B1-B3 indicate that the dermal contact ILCRs for adults, chil- 
Inhalation exposure
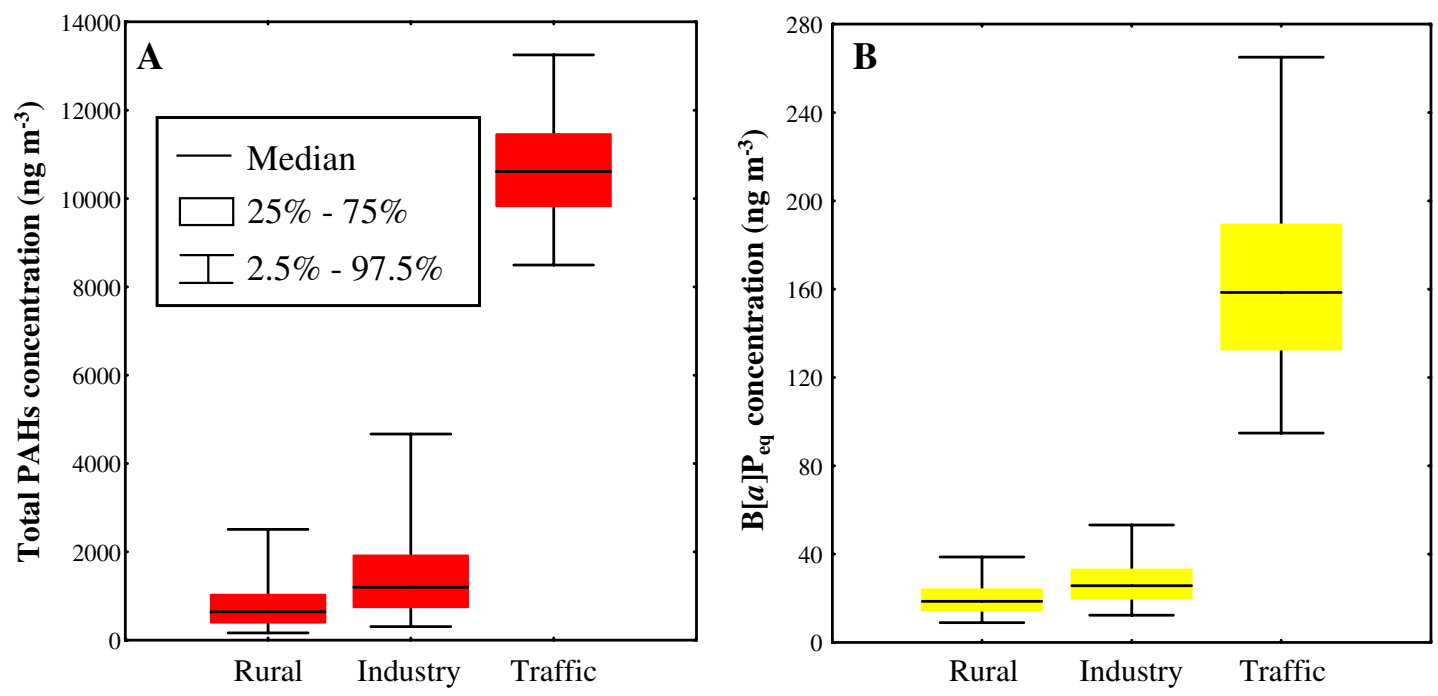

Dermal exposure
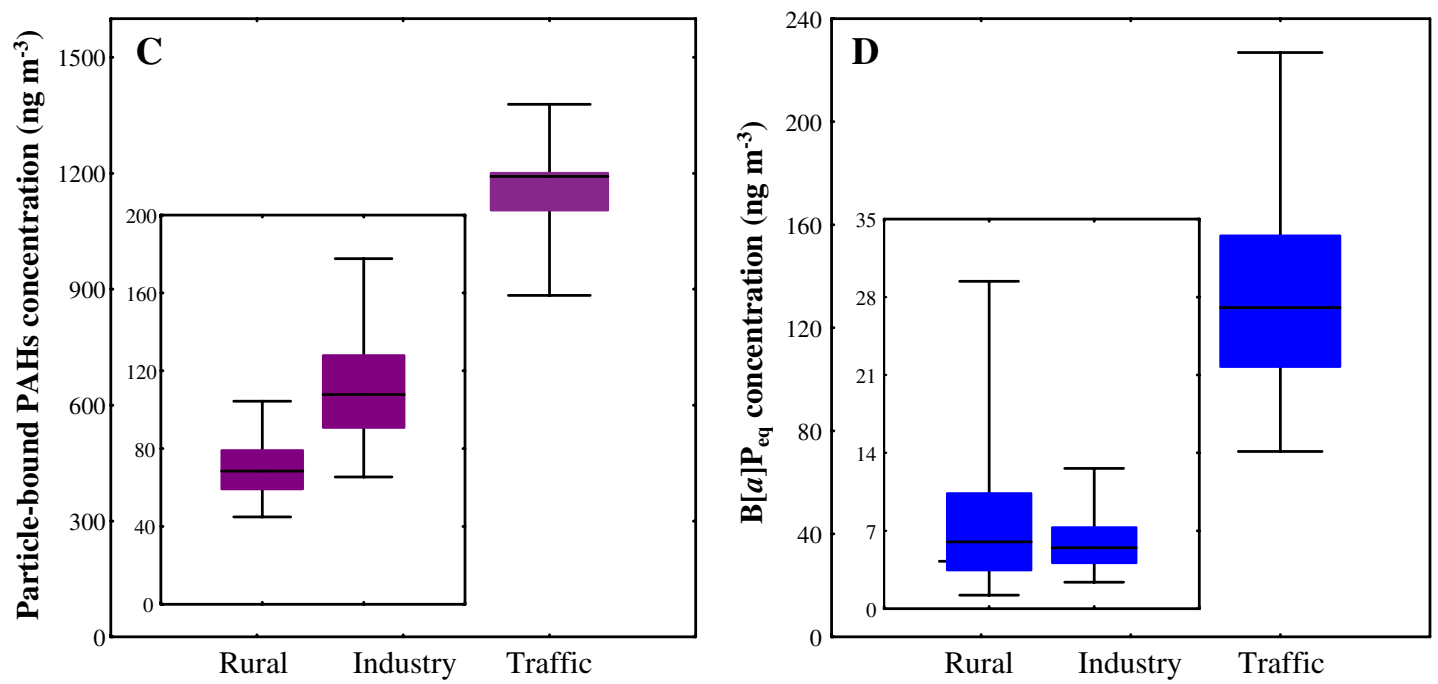

Fig. 2. Box and whisker plots of exposure levels of (A) total PAHs and (B) $\mathrm{B}[a] \mathrm{P}_{\mathrm{eq}}$ for inhalation, (C) particle-bound $\mathrm{PAHs}$ and (D) $\mathrm{B}[a] \mathrm{P}_{\mathrm{eq}}$ for dermal at rural, industry, and traffic settings, respectively.

dren, and infants age group have LN distributions of $\mathrm{LN}\left(3.85 \times 10^{-5}, 2.75\right), \quad \mathrm{LN}\left(5.16 \times 10^{-6}, 3.33\right)$, and $\mathrm{LN}\left(9.90 \times 10^{-8}, 4.83\right)$, respectively.

For adults and children age groups, inhalation ILCR values are higher than that of dermal contact, whereas for infants age group, dermal contact ILCR value is higher than that of inhalation. Percentile predictions of total ILCR personal exposure of three age groups could be determined from cumulative density functions (cdfs) corresponding to pdfs shown in Fig. 4C1, D1, and E1. The total ILCR that combines dermal contact and inhalation exposure pathways are estimated to be
$\mathrm{LN}\left(1.66 \times 10^{-4}, 1.89\right), \quad \mathrm{LN}\left(1.44 \times 10^{-5}, 2.13\right)$, and $\mathrm{LN}\left(2.10 \times 10^{-7}, 2.93\right)$, for adults, children, and infants, respectively.

Under most regulatory program, an ILCR between $10^{-6}$ and $10^{-4}$ indicates potential risk. Our results indicate that the $97.5 \%$ probability inhalation and dermal contact ILCRs for adults and children exposed to PAH have orders of magnitude around $10^{-5}$ and $10^{-4}$, indicating high potential carcinogenic risk (Fig. 4A1, A2, B1, B2). All $97.5 \%$ probabilities of $\mathrm{B}[a] \mathrm{P}_{\text {eq }}$-based total ILCRs (TILCRs) are large than $10^{-6}$, indicating unacceptable probability distributions 
Inhalation exposure

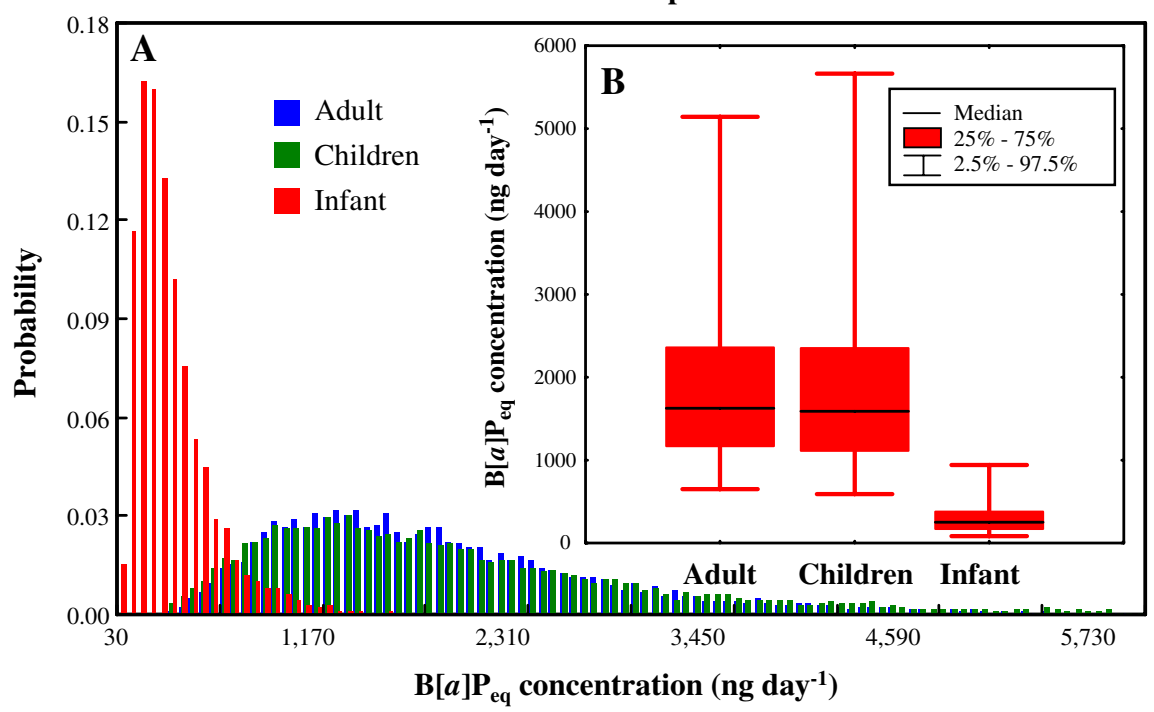

Dermal exposure

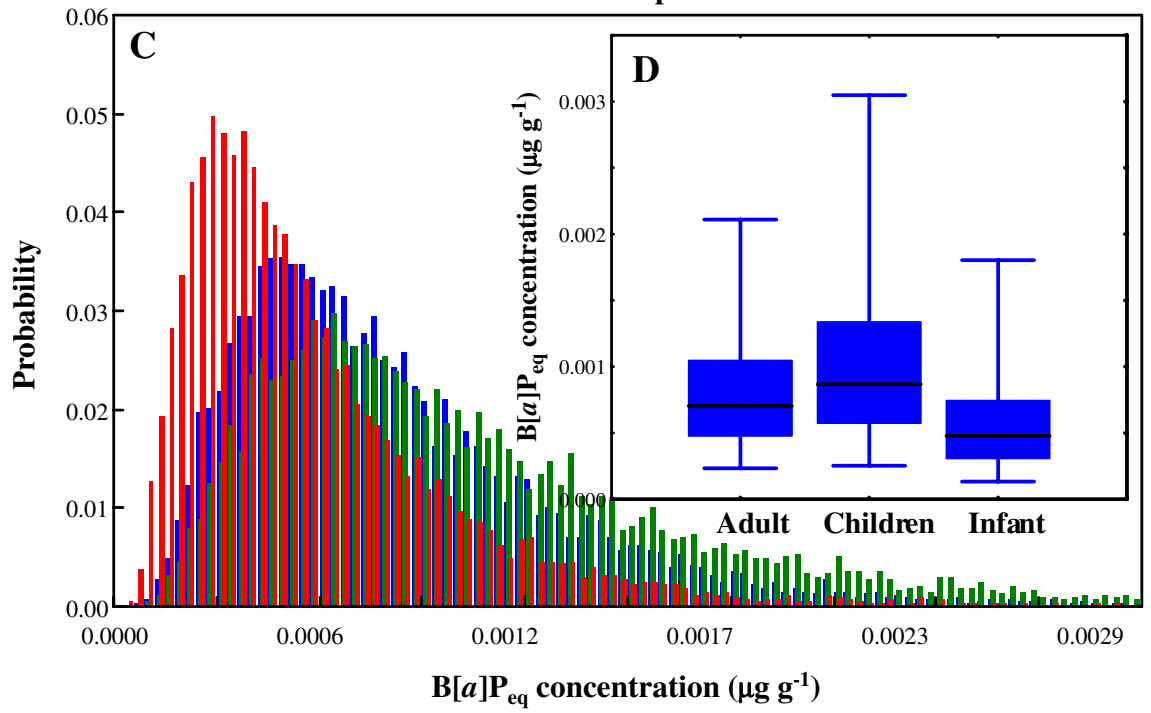

Fig. 3. Predicted probability density functions of $\mathrm{B}[a] \mathrm{P}_{\mathrm{eq}}$ concentration $(\mathrm{A}, \mathrm{C})$ and the box and whisker plots $(\mathrm{B}, \mathrm{D})$ describing the three age groups for inhalation and dermal exposure to environmental PAHs sources, respectively.

for three age groups (Fig. 4C2, D2, E2). For adult personal exposure to carcinogenic $\mathrm{PAH}, 97.5 \%$ probability TILCR $\left(5.89 \times 10^{-4}\right)$ is much fall outside the range of $10^{-6}-10^{-4}$, indicating high potential health risk; whereas for children and infants age groups, $97.5 \%$ probability TILCRs range from $10^{-6}-10^{-5}$ (children: $7.05 \times 10^{-5}$ and infant: $2.41 \times 10^{-6}$ ), respectively (Fig. 4C2, D2, E2). The infants and children have the lower values of $\mathrm{AF}_{\mathrm{d}}, \mathrm{ED}$ and $\mathrm{BW}$ than those of adults (Table 2) that may provide an explanation for the infants and children who are at low risks.

\subsection{Sensitivity analysis}

We conducted a quantitative sensitivity analysis to evaluate the variability and uncertainty of parameters in the exposure pathway that contributed most significantly to the risk estimates. The results of the sensitivity analyses on inhalation and dermal contact risk models are shown in the form of tornado plots illustrating the Spearman rank order correlation coefficients (Fig. 5). For inhalation exposure, the inhalation cancer slope factors $\left(\mathrm{CSF}_{\mathrm{i}}\right)$ and daily inhalation exposure level $\left(E_{I}\right)$ are the most influential variables for all three age 


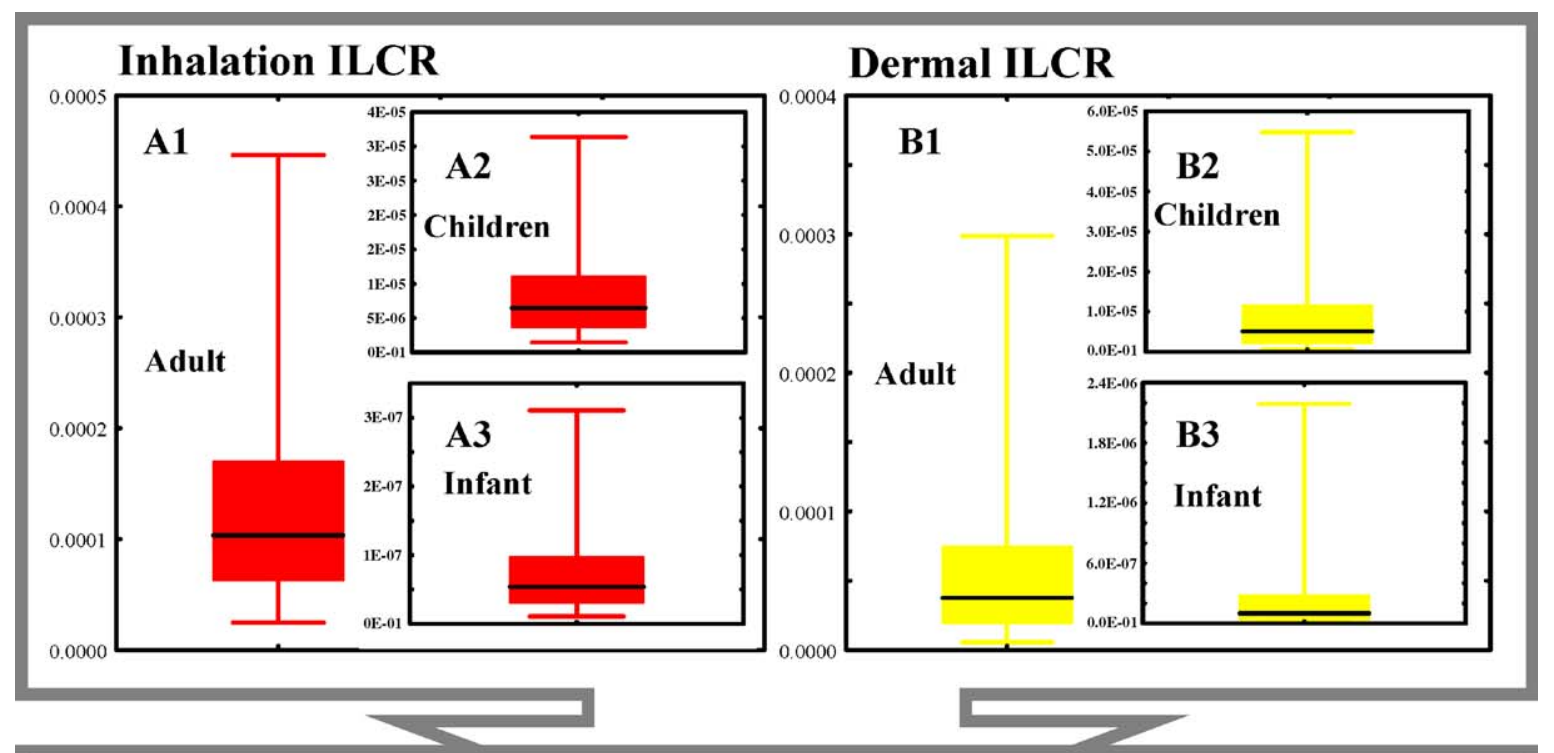

\section{Total ILCR}
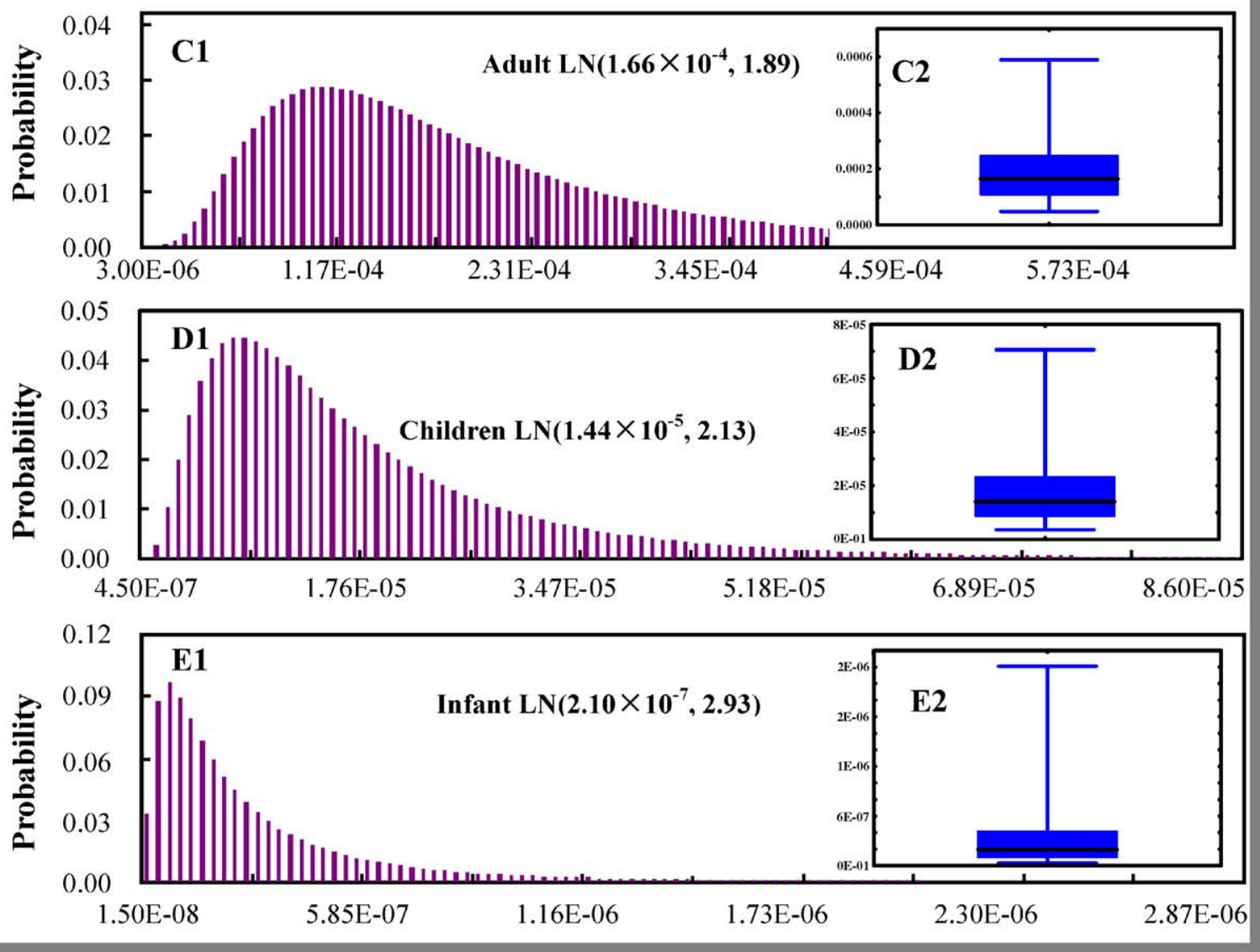

Fig. 4. Box and whisker plots for (A1) adult, (A2) children, and (A3) infant of inhalation incremental lifetime cancer risk and for (B1) adult, (B2) children, and (B3) infant of dermal contact incremental lifetime cancer risk. Predicted probability density functions of total incremental lifetime cancer risk for (C1) adult, (D1) children, and (E1) infant and the box and whisker plots (C2, D2, and E2) are also shown. 
A
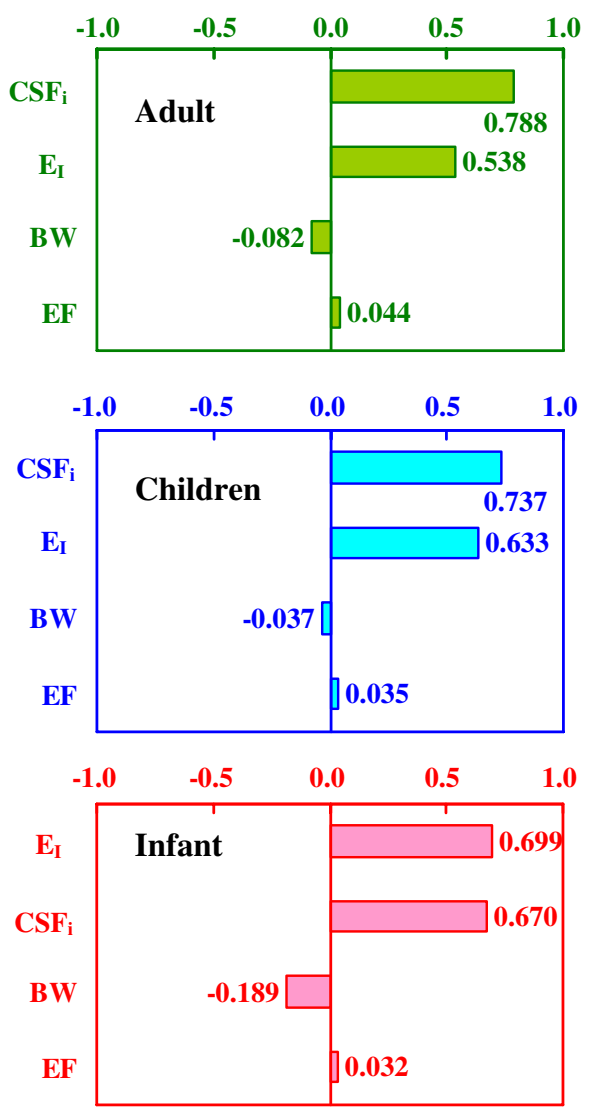

B
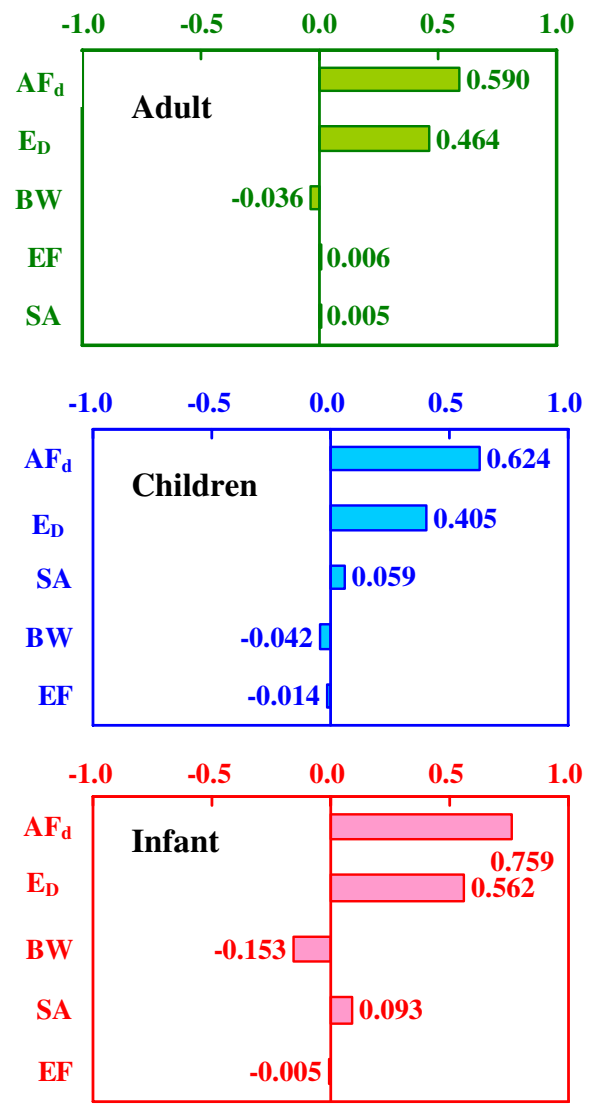

Fig. 5. Sensitivity analysis for (A) inhalation incremental lifetime cancer risk model and (B) dermal contact incremental lifetime cancer risk model for three age groups.

groups, which average contributions to output variance are $67 \%, 69 \%$ and $69 \%$, respectively, for adults, children, and infants. For dermal exposure to particlebound PAH, the particle-to-skin adherence factor $\left(\mathrm{AF}_{\mathrm{d}}\right)$ and daily dermal exposure level $\left(E_{\mathrm{D}}\right)$ is the most influential variable for all three age groups, which the contributions to output variance range from $59-76 \%$ and $46-56 \%$, respectively (Fig. 5).

\section{Discussion}

The study of human exposure to environmental PAH pollution sources identified the age-specific potential cancer risks. Recognition of the importance of inhalation cancer slope factor and particle-bound PAH-to-skin adherence factor in PAH exposure led to the efforts to estimate the significance of inhalation and dermal ILCRs. Sensitivity analysis indicates that to increase the accuracy of the results efforts should focus on a better definition of probability distributions for inhalation cancer slope factor and particle-bound PAH-to-skin adherence factor. Given the scarcity of data, most of the probability distributions were based on US EPA data, and this may be a limit to the validity of the case presented.

The CSF values (upper 95\% CI estimate of initial dose-response curve) for continuous inhalation exposure to $\mathrm{B}[a] \mathrm{P}$ obtained from several data sets (respiratory tract tumors in hamsters and gastric tumors in mice) by Collins et al. (1991) range between 1.3-16.9 $\left(\mathrm{mg} \mathrm{kg}^{-1} \mathrm{day}^{-1}\right)^{-1}$ of $\mathrm{B}[\mathrm{a}] \mathrm{P}$. The differences are due in part to the different treatment procedures and to assumptions adopted on animal physiological parameters (e.g., surface area scaling factor). Ingestion exposure data were used for inhalation exposure assessment by considering the intake dose with routeto-route extrapolation.

It must also be noted that uncertainties are inherent in quantitative risk assessment because of assumptions required to extrapolate from one species to another, from high to low situations and because of the statistical modeling techniques required to fit data points. Extrap- 
olation to low doses and the transferring of results from test animals to humans is not evident at all. Therefore, rodent-derived risk factors may have different orders of magnitude comparing with empirical data derived risk estimates.

Tsai et al. (2001) conducted a health risk assessment for palletizing and packaging workers exposed to PAHs in a carbon black manufacturing industry, indicating $\mathrm{B}[a] \mathrm{P}_{\mathrm{eq}}$-based lifetime lung cancer risks estimated for both exposure groups were $4.35 \times 10^{-2}$ and $5.42 \times 10^{-2}$, respectively. For dermal exposure, $\mathrm{B}[a] \mathrm{P}_{\text {eq }}$-based lifetime skin cancer risks for both exposure groups were estimated to be $1.13 \times 10^{-3}$ and $1.56 \times 10^{-3}$, respectively. Vyskocil et al. (2004) assessed the lung cancer in six localities with aluminum smelting activities exposed to PAHs, indicating the upper bound $\mathrm{B}[a] \mathrm{P}_{\mathrm{eq}}$-based lifetime cancer risk estimates ranged from $0.94-4.7 \times 10^{-5}$. Our risk analysis indicates that average upper bound $\mathrm{B}[a] \mathrm{P}_{\mathrm{eq}^{-}}$based inhalation ILCR for three age groups was $1.59 \times$ $10^{-4}\left(3.10 \times 10^{-7}-4.46 \times 10^{-4}\right)$, whereas for dermal ILCR was $1.19 \times 10^{-4}\left(2.19 \times 10^{-6}-2.99 \times 10^{-4}\right)$.

The $\mathrm{B}[a] \mathrm{P}_{\text {eq }}$-based approach is necessarily limited to a few PAHs that have monitored in ambient air and dose not account for the toxicity of all PAHs to which the general population is exposed. Moreover, the additivity assumption of this approach is quite uncertain and may lead to inaccurate assessments. Despite this limitation, this approach has the merit of taking into account the actual PAH profiles encountered in environmental settings reported in this study.

The carcinogenic risk assessment of PAH remains difficult, particularly due to the very high number of these compounds (in the hundreds) present in mixtures to which the general population may be exposed, as well as due to the possible contemporary presence of other risk factors and to possible synergistic and/or antagonistic effects. Due to the limited number of dose-response data on carcinogenicity, and depending on the exposure route (intratracheal administration, intrapulmonary injection, and so on), different PEFs can be obtained (Goldstein, 2001). For example, the PEF value used in this study for $\mathrm{DB}[a, h] \mathrm{A}$ is 1.0 , as given by Malcom and Dobson (1994). This value may underestimate the relevance of this compound, because other authors claim a PEF of 5.0 (Nisbet and LaGoy, 1992). It has also to be remembered that the $\mathrm{B}[a] \mathrm{P}_{\text {eq }}$ concentrations used for this calculation represent an external exposure estimation of carcinogenic compounds and not the effective active concentration at the lung level.

There are a number of areas in which further research could reduce the uncertainties and limit the variabilities in this study. Among these are three areas that offer an opportunity for the most useful research. First, there is a need to conduct a more extensive characterization of the distribution of exposures within given population groups. This would require the collection of more detailed information on the characterization of occupation probabilities, PAH uptake in the lung and skin, and daily working logs. It would be useful to characterize better the distribution of exposures by age of individuals exposed. Second, there is a need for global sensitivity analysis using the Monte Carlo simulation model with the more detailed data sets as inputs. The ranges and distributions of parameters can then be combined by use of the Monte Carlo simulation model to produce a response surface. Relationships between the input ranges and model output should then be assessed with stepwise regression in order to identify the relationship between output variability and input uncertainties and variabilities. Finally, on the basis of the results of the sensitivity analysis, research should be directed to those parameters that, if better characterized, could most effectively reduce variability in the results.

\section{References}

Alexandrov K, Cascorbi I, Rojas M, Bouvier G, Kriek E, Bartsch H. CYP1A1 and GSTM1 genotypes affect benzo[a]pyrene DNA adducts in smokers' lung: comparison with aromatic/hydrophobic adduct formation. Carcinogenesis 2002;23(12):1969-77.

Ando M, Katagiri K, Tamura K, Yamamoto S, Matsumoto M, Li YF, et al. Indoor and outdoor air pollution in Tokyo and Beijing supercities. Atmos Environ 1996;30:695-702.

Armstrong B, Hutchinson E, Unwin J, Fletcher T. Lung cancer risk after exposure to polycyclic aromatic hydrocarbons: a review and meta-analysis. Environ Health Perspect 2004;112:970-8.

ATSDR. Toxicological profile for benzo[a]pyrene. Agency for toxic substance and disease registry. Atlanta, GA: United States Public Health Service; 1990.

Boffetta P, Jourenkova N, Gustavsson P. Cancer risk from occupational and environmental exposure to polycyclic aromatic hydrocarbons. Cancer Causes Control 1997;8:444-72.

Collins JF, Brown JP, Dawson SV, Marty MA. Risk assessment for benzo[a]pyrene. Regul Toxicol Pharm 1991;13:170-84.

Collins JF, Brown JP, Alexeeff GV, Salmon AG. Potency equivalency factors for some polycyclic aromatic hydrocarbons and polycyclic aromatic hydrocarbons derivatives. Regul Toxicol Pharm 1998; $28: 45-54$

Deutsch-Wenzel RP, Brune H, Grimmer G, Dettbarn G, Misfeld J. Experimental studies in rat lungs on the carcinogenicity and doseresponse relationships of eight frequently occurring environmental polycyclic aromatic hydrocarbons. J Natl Cancer Inst 1983;71: $539-44$

Fang GC, Wu YS, Chen MH, Ho TT, Huang SH, Rau JY. Polycyclic aromatic hydrocarbons study in Taichung, Taiwan, during 20022003. Atmos Environ 2004a;38:3385-91.

Fang GC, Chang KF, Lu C, Bai H. Estimation of PAHs dry deposition and BaP toxic equivalency factors (TEFs) study at Urban, Indus- 
try Park and rural sampling sites in central Taiwan, Taichung. Chemosphere 2004b;55:787-96.

Fang GC, Wu YS, Fu PC, Yang IL, Chen MH. Polycyclic aromatic hydrocarbons in the ambient air of suburban and industrial regions of central Taiwan. Chemosphere 2004c;54:443-52.

Fisher PH, Hoek G, van Reeuwijk H, Briggs DJ, Lebret E, van Wijnen JH, et al. Traffic-related differences in outdoor and indoor concentrations of particles and volatile organic compounds in Amsterdam. Atmos Environ 2000;34:3713-22.

Gaspari L, Chang SS, Santella RM, Garte S, Pedotti P, Taioli E. Polycyclic aromatic hydrocarbon-DNA adducts in human sperm as a marker of DNA damage and infertility. Mutat Res 2003; 535:155-60.

Goldstein LS. To $\mathrm{BaP}$ or not to $\mathrm{BaP}$ ? That is the question. Environ Health Perspect 2001;109:A356-7.

ICRP (The international Commission on Radiological Protection). Human respiratory tract model for radiological protection. ICRP Publication. New York, NY: Elsevier; 1994. ICRP.

Hussain M, Rae J, Gilman A, Kauss P. Lifetime health risk assessment from exposure of recreational users to polycyclic aromatic hydrocarbons. Arch Environ Contam Toxicol 1998;35:527-31.

Kingham S, Briggs D, Elliott P, Fischer P, Lebret E. Spatial variations in the concentrations of traffic-related pollutants in indoor and outdoor air in Huddersfield, England. Atmos Environ 2000; 34:905-16.

Li CS, Ro YS. Indoor characteristics of polycyclic aromatic hydrocarbons in the urban atmosphere of Taipei. Atmos Environ 2000; 34:611-20.

Malcom HM, Dobson S, 1994. The calculation of an environmental assessment level (EAL) for atmospheric PAHs using relative potencies. London, UK: Department of the Environment; 1994. p. $34-46$.

Naumova YY, Eisenreich SJ, Turpin BJ, Weisel CP, Morandi MT, Colome SD, et al. Polycyclic aromatic hydrocarbons in the indoor and outdoor air of three cities in the US. Environ Sci Technol 2002;36:2552-9.

Nisbet ICT, LaGoy PK. Toxic equivalency factors (TEFs) for polycyclic aromatic hydrocarbons (PAHs). Regul Toxicol Pharm 1992;16:290-300.

OEHHA (The international Commission on Radiological Protection). Benzo $[a]$ pyrene as a toxic air contaminant, Part B, health effects of Benzo[a]pyrene. Berkeley, CA: Air Toxicology and Epidemiology Section; 1993.
Perera F, Hemminke K, Jedrychowski W, Whyatt R, Campbell U, Hsu $\mathrm{Y}$, et al. In utero DNA damage from environmental pollution is associated with somatic gene mutation in newborns. Cancer Epidemiol Biomark Prev 2002;11:1134-7.

Schmahl D, Schmidt KG, Habs M. Syncarcinogenic action of polycyclic aromatic hydrocarbons in automobile exhaust gas condensates. IARC Scientific Publication. Lyon, France: WHO; 1977.

Somers CM, Yauk CL, White PA, Parfett CLJ, Quinn JS. Air pollution induces heritable DNA mutations. Proc Natl Acad Sci U S A 2002;99:15904-7.

Somers CM, McCarry BE, Malek F, Quinn JS. Reduction of particulate air pollution lowers the risk of heritable mutations in mice. Science 2004;304:1008-10.

Thyssen J, Althoff J, Kimmerle G, Mohr U. Inhalation studies with benzo $[a]$ pyrene in Syrian golden hamsters. J Natl Cancer Inst 1981;66:575-7.

Tsai PJ, Shieh HY, Lee WJ, Lai SO. Health risk assessment for workers exposed to polycyclic aromatic hydrocarbons (PAHs) in carbon black manufacturing industry. Sci Total Environ 2001; 278:137-50.

Tsai PJ, Shih TS, Chen HL, Lee WJ, Lai CH, Liou SH. Assessing and predicting the exposures of polycyclic aromatic hydrocarbons (PAHs) and their carcinogenic potencies from vehicle engine exhausts to highway toll station workers. Atmos Environ 2004; 38:333-43.

USEPA. Dermal exposure assessment: principles and applications. Office of Health and Environmental Assessment; 1992. EPA/ 600/6-88/005Cc.

USEPA. Risk assessment Guidance for superfund, volume I: human health evaluation manual (Part E, Supplemetal Guidance for dermal risk assessment), EPA/540/R/99/005. Washington DC, USA: Office of Emerage and Remedial Response; 2001.

Venkataraman C, Raymond J. Estimating the lung deposition of particulate polycyclic aromatic hydrocarbons associated with multimodal urban aerosols. Inhal Toxicol 1998;10:183-204.

Vyskocil A, Viau C, Camus M. Risk assessment of lung cancer related to environmental PAH pollution sources. Human Exp Toxicol 2004;23:115-27.

Yang HH, Lai SO, Hsieh LT, Hsueh HJ, Chi TW. Profiles of PAH emission from steel and iron industries. Chemosphere 2002; 48:1061-74.

Yang HH, Hsieh LT, Liu HS, Mi HH. Polycyclic aromatic hydrocarbon emissions from motorcycles. Atmos Environ 2005;39:17-25. 